\title{
Refractory Sarcoma
}

National Cancer Institute

\section{Source}

National Cancer Institute. Refractory Sarcoma. NCI Thesaurus. Code C148301.

A sarcoma that does not respond to treatment. 